\title{
Use of Social Media by Hospitals and Clinics in Japan: Descriptive Study
}

\author{
Yuya Sugawara $^{1,2,3}$, PhD; Masayasu Murakami ${ }^{2}, \mathrm{PhD}$; Hiroto Narimatsu ${ }^{3,4}, \mathrm{MD}, \mathrm{PhD}$ \\ ${ }^{1}$ Institute for Promotion of Medical Science Research, Faculty of Medicine, Yamagata University, Yamagata, Japan \\ ${ }^{2}$ Department of Health Policy Science, Graduate School of Medical Science, Yamagata University, Yamagata, Japan \\ ${ }^{3}$ Cancer Prevention and Control Division, Kanagawa Cancer Center Research Institute, Yokohama, Japan \\ ${ }^{4}$ Graduate School of Health Innovation, Kanagawa University of Human Services, Kawasaki, Japan
}

\section{Corresponding Author:}

Hiroto Narimatsu, MD, PhD

Cancer Prevention and Control Division

Kanagawa Cancer Center Research Institute

2-3-2 Nakao Asahi-ku

Yokohama, 241-8515

Japan

Phone: 81455202222

Email: hiroto-narimatsu@umin.org

\section{Abstract}

Background: The use of social media by hospitals has become widespread in the United States and Western European countries. However, in Japan, the extent to which hospitals and clinics use social media is unknown. Furthermore, recent revisions to the Medical Care Act may subject social media content to regulation.

Objective: The purpose of this study was to examine social media use in Japanese hospitals and clinics. We investigated the adoption of social media, analyzed social media content, and compared content with medical advertising guidelines.

Methods: We randomly sampled 300 hospitals and 300 clinics from a list of medical institutions that was compiled by the Ministry of Health, Labour and Welfare. We performed web and social media (Facebook and Twitter) searches using the hospital and clinic names to determine whether they had social media accounts. We collected Facebook posts and Twitter tweets and categorized them based on their content (eg, health promotion, participation in academic meetings and publications, public relations or news announcements, and recruitment). We compared the collected content with medical advertising guidelines.

Results: We found that 26.0\% (78/300) of the hospitals and 7.7\% (23/300) of the clinics used Facebook, Twitter, or both. Public relations or news announcements accounted for 53.99\% (724/1341) of the Facebook posts by hospitals and 58.4\% (122/209) of the Facebook posts by clinics. In hospitals, 16/1341 (1.19\%) Facebook posts and 6/574 (1.0\%) tweets and in clinics, 8/209 (3.8\%) Facebook posts and 15/330 (4.5\%) tweets could conflict medical advertising guidelines.

Conclusions: Fewer hospitals and clinics in Japan use social media as compared to other countries. Social media were mainly used for public relations. Some content disseminated by medical institutions could conflict with medical advertising guidelines. This study may serve as a reference for medical institutions to guide social media usage and may help improve medical website advertising in Japan.

(JMIR Med Inform 2020;8(11):e18666) doi: 10.2196/18666

\section{KEYWORDS}

social media; internet; hospitals; health promotion; Japan

\section{Introduction}

More than 4.5 billion people use the internet, and the number of social media users worldwide has passed the 3.8 billion mark as of the start of 2020 [1]. Facebook and Twitter are popular social media tools. As of the second quarter of 2020, Facebook had over 2.7 billion monthly active users (MAUs) [2]. As of the first quarter of 2019, Twitter had an average of 330 million MAUs worldwide [3]. In Japan, in 2019, Facebook had 26 million MAUs, and Twitter had about 48 million MAUs [4].

A major benefit of social media for health communication is the accessibility and widening access of health information to 
various population groups, regardless of age, education, race or ethnicity, and locality [5]. Thus, many health care organizations use social media. In the United States, $94.41 \%$ of hospitals have Facebook pages, and $50.82 \%$ have Twitter accounts [6]. In Western Europe, $67.0 \%$ of hospitals have Facebook pages, and $18.1 \%$ have Twitter accounts [7]. Thaker et al [8] reported that hospitals use social media to announce news and events and to promote themselves and health.

While many hospitals disseminate beneficial health information, there is concern that some hospital social media content may breach patient privacy [9]. Some hospitals may disseminate blatant advertising [10]. Some plastic surgeons emphasize immediate positive results, without discussing any potential complications or postoperative care requirements, and photoshopped before and after pictures are commonplace in some social media posts [10]. Japan's Medical Care Act was amended in 2017 and the new Medical Care Act has been enforced since 2018 [11,12]. With this revision, websites of medical institutions that were previously not considered advertisements are now considered so and are also now subject to regulation. To this end, administrative and criminal penalties have been introduced for violations. In addition, medical advertisement guidelines were also revised by the Ministry of Health, Labour and Welfare (MHLW) [13]. The contents of health care organizations' websites have been restricted because of these revisions. Although the guidelines do not mention social media, they may be identified as websites, and the contents of health care organizations' social media can thus be restricted. However, Japanese hospitals and clinics may disseminate health information that do not follow medical advertisement guidelines.

Presently, the extent to which Japanese health care organizations use social media is unknown, necessitating investigation. Accordingly, this study was designed to investigate the outline of social media use in Japanese hospitals and clinics through the following research questions:

1. How many social media accounts do Japanese medical institutions have?

2. What kind of information do Japanese medical institutions post on social media?

3. Does the information posted by the medical institutions conform to the medical advertising guidelines?

\section{Methods}

\section{Study Population}

We extracted study samples based on lists that were available. The list of insurance-covered medical institutions is maintained by the Regional Bureau of Health and Welfare, MHLW [14,15]. The list of clinics that performed treatment not covered by health insurance was published on Yahoo! Healthcare [16]. We extracted 8600 hospitals, 154,213 clinics, and 515 clinics that performed treatment not covered by health insurance, from the lists of medical institutions.

In Japan, the universal insurance system was established in 1961 [17]. This system allows anyone to visit medical institutions anytime and anywhere with no discrimination [18,19].
Therefore, we assumed that there was no difference in regional medical care provision and the use of social media. In this study, 300 samples were uniformly extracted from hospitals and clinics in Japan without considering regional bias. We assigned a random number to each hospital and clinic using an Excel (Microsoft) function. After assigning a random number, 300 samples were extracted in the descending order of random numbers. The size of the extracted sample was estimated based on the interval estimation of the population proportion. We performed a pilot study from February 23, 2018, to March 12, 2018 , extracting 200 samples for trial. The results indicated that $26.5 \%(53 / 200)$ of hospitals used social media. We estimated that the sample size was 300 by using the statistical software EZR with the width of the $95 \%$ confidence interval as 0.1 , so that the actual results fit within $\pm 5 \%$ of the true value with the expected proportion being 0.265 . Moreover, the 200 test samples were not included in the 300 samples used in the main study.

The date of designation as insurance-covered medical institutions, the name of the medical institutions, address, phone number, ID of medical institutions, and specialty are contained in the list of insurance-covered medical institutions. This list has been published on a website maintained the Regional Bureau Health and Welfare of each region [20-27]. Anyone can freely download the list as a PDF file (Adobe) or MS Excel file. We used the data of insurance-covered medical institutions as of October 1, 2017, in this study. We accessed Yahoo! Healthcare to collect the data not covered by health insurance clinics on November 5, 2017. However, Yahoo! Healthcare, which published information on health care and medical institutions on its website, was shut down on March 29, 2018 [16].

\section{Social Media Accounts of Hospitals and Clinics}

Facebook and Twitter, the major social media in Japan, were selected for analysis. For each sample of 300 hospitals and clinics, we performed Google searches using the names of the hospitals and clinics. We checked whether social media accounts of hospitals and clinics exist. Using the search engine on the official social media page as well as Google, the name of each medical institution was searched to check for the existence of a social media account. For medical institutions that have social media accounts, their websites were checked to see whether a social media policy has been formulated.

We surveyed the numbers of "likes" and "followers" from the medical institutions' Facebook and Twitter pages. The attributes of each hospital and clinic (clinical department, number of beds, types of beds, who established it) were drawn from the extracted hospitals and clinics' websites and the list of insurance-covered medical institutions.

The survey of the social media accounts of hospitals and clinics was conducted from April 7 to April 22, 2018. We accessed social media accounts of hospitals from April 7 to 15, 2018, and clinics from April 15 to 19, 2018. The data gathering of social media accounts was completed on April 22, 2018.

\section{Data Collection}

We collected content from Facebook and Twitter. For each hospital and clinic account, we collected 100 Facebook posts and 1000 tweets. Content data were collected using NodeXL 
Excel Template 2014 (version 1.0.1.402; The Social Media Research Foundation), an MS Excel add-in [28]. After collecting Facebook posts and tweets, to investigate the difference in the number of comments for each season, the number of monthly comments in 2017 for each hospital and clinic was calculated. Then, Facebook post and Twitter tweet data were collected between August 4 and 5, 2018.

\section{Classification of Contents}

The latest 20 Facebook posts and the latest 100 tweets were manually categorized by content per medical institution. Contents were categorized manually and classified into 4 types: "Health promotion," "Participation in academic meetings, publications," "Public relations, news announcements," and "Recruitment." At first, it was divided into "Health promotion," "Public relations, news announcements," and "Recruitment" with reference to previous studies $[5,8,29,30]$. As we continued the classification, we found that there was a lot of content related to participation in academic meetings and publications. Therefore, a new item "Participation in academic meetings, publications" was added. We categorized social media contents as shown in Textbox 1.

If the social media content was updates on the medical institution's blog, we checked the links and categorized the comments. If more than 1 content is included, the main topic is judged from the context and the comments are categorized.

Three researchers (a medical informatics specialist [YS], a health policy specialist $[\mathrm{MM}]$, a medical doctor and public health specialist $[\mathrm{HN}]$ ) categorized contents into 4 types. When a conflict occurred, it was resolved by discussions between the 3 researchers. Thus, all content was categorized upon agreement from the 3 researchers.

Textbox 1. Social media contents.

- Health Promotion: Dissemination of medical knowledge and health information. This includes easy-to-understand medical knowledge and health information for patients and the public, and professional information for professionals.

- Participation in Academic Meetings, Publications: Comments on academic activities such as information on holding academic meetings, participation in academic meetings, writing papers, and specialized books.

- Public Relations, News Announcements: Reports on in-hospital events for patients, notifications from hospitals, public relations, comments related to consultation (eg, hospitals are closed, change in consultation hours).

- Recruitment: Content related to human resources, such as personnel change reports and comments on recruitment.

- Others: Comments that do not apply to any of the above. For example, comments on activities that are not related to the actual work, such as welcome parties, social gatherings, and sports competitions.

\section{Comparison With Guidelines}

We compared the collected contents with the medical advertising guidelines and examined whether they complied with the guidelines or were appropriate as advertisements. In addition to the medical advertising guidelines, the "Doctor's Professional Ethics Guidelines," "The way medical facility websites should be - Guidelines for providing member medical facilities and medical information" (2008 March revised edition; both issued by the Japan Medical Association), and a previous study that compared medical advertising guidelines and the websites of medical institutions related to aesthetic medicine were used to create evaluation items and criteria (Multimedia Appendix 1) [31-33]. Referring to the criteria and the advertising example described in the medical advertising guidelines, 3 researchers (a medical informatics specialist [YS], a health policy specialist [MM], a medical doctor and public health specialist [HN]) compared contents and medical advertising guidelines. Based on the agreement of the 3 researchers, it was decided whether it was appropriate as a medical advertisement.

\section{Text Mining}

To complement manual content analysis, text mining was performed on Facebook posts and tweets of the hospitals and clinics, respectively. We calculated term frequency-which is the number of occurrences of each target word in an entire text-and created a co-occurrence network. We used KH Coder Version 3.Beta.01g for Windows for this task [34-36]. ChaSen, which was used for the morphological analysis, was included in $\mathrm{KH}$ Coder and used for word extraction. $\mathrm{KH}$ Coder uses the Jaccard coefficient to determine the degree of word-to-word co-occurrence and creates a network chart [37]. In this chart, words closely associated with each other are connected with lines [37]. KH Coder also displays networks that are more closely associated with each other as "subgraphs" through color coding [37]. In this context, co-occurrence means there is a close relationship between words [38].

\section{Statistical Analysis}

The percentage of the social media account holding ratio for each medical institution was calculated. We regarded a medical institution that has either or both a Facebook and Twitter account as "Having a social media account." We calculated the median and IQR for the numbers of beds, Facebook likes, and Twitter followers.

Fisher exact test and logistic regression analysis were performed on the attributes of medical institutions and whether medical institutions have social media accounts.

Hospital attributes were hospital size (small and medium hospitals with 20-199 beds, large hospitals with more than 200 beds), urban/rural, hospital classification (general hospital, internal medicine hospital, surgical hospital), who established it (individual/nonprofit medical corporations, national/public/social insurance-related organizations), Regional Bureau of Health and Welfare in each region, hospital functions (general hospitals, special functioning hospitals or regional 
medical care support hospitals), and whether the hospital has a website.

Clinic attributes were whether the clinic has a bed, urban/rural, medical/dental classification, Regional Bureau of Health and Welfare in each region, who established it (individuals, nonprofit medical corporations, national/public), specialty (internal medicine departments, surgical departments, dentistry), and whether the clinic has a website.

In the logistic regression analysis, the presence or absence of social media accounts was analyzed as a dependent variable, and the attributes of medical institutions were analyzed as independent variables.

We compared the ratio of sample medical institutions by region with actual medical institutions. The goodness-of-fit test was performed by the chi-square test with reference to the reports released by the MHLW [39].

A $P$ value $<.05$ was considered statistically significant. Statistical analyses were performed with EZR (version 1.37, Saitama Medical Center, Jichi Medical University), which is a graphical user interface for R (The R Foundation for Statistical Computing). More precisely, it is a modified version of $\mathrm{R}$ commander designed to add statistical functions frequently used in biostatistics [40].

This study was approved by the Institutional Review Board of Yamagata University, Faculty of Medicine.

\section{Results}

\section{Sample Medical Institutions}

We extracted 600 medical institutions (300 hospitals and 300 clinics). Of the 300 hospitals, 209 were small and medium hospitals, and 91 were large hospitals; 10 hospitals were special functioning hospitals or regional medical care support hospitals. Of the 300 clinics, 176 were medical clinics and 124 were dental clinics. For the ratio of number of sample medical institutions to the actual number of medical institutions by each Regional Bureau of Health and Welfare, a chi-square test revealed no significant difference in hospitals $\left(P=.268, \chi^{2}{ }_{7}=8.791\right)$ or clinics $\left(P=.958, \chi_{7}^{2}=2.028\right)$. Multimedia Appendix 2 shows a table comparing the ratio of sample medical institutions to actual medical institutions.

\section{Research Question 1}

\section{Hospital Accounts}

Table 1 shows the number and ownership of social media accounts of medical institutions. Of the 300 hospitals and clinics, $78(26.0 \%)$ and $23(7.7 \%)$, respectively, have Facebook or Twitter accounts or both.

Tables 2 and 3 show the results of Fisher exact test and logistic regression analysis for the use of social media and the attributes of hospitals, respectively. The Fisher exact test showed a significant difference in the presence or absence of social media and hospital size $(P<.001)$, hospital classification $(P=.018)$, hospital function $(P=.004)$, and website presence $(P=.025)$. Logistic regression analysis showed a significant difference in hospital size $(P<.001)$. The odds ratio was 3.25 with a $95 \%$ confidence interval ranging from 1.75 to 6.04 . No significant difference was found except for hospital size. The ranges of all generalized variance inflation factor in the logistic regression analysis ranged from 1.00 to 1.39 .

Table 1. Numbers and percentages of social media accounts and websites that medical institutions had $(\mathrm{N}=300)$.

\begin{tabular}{lllll}
\hline Institutions & Social media & Facebook & Twitter & Website \\
\hline Hospitals, $\mathrm{n}(\%)$ & $78(26.0)$ & $73(24.3)$ & $13(4.3)$ & $286(95.3)$ \\
Clinics, $\mathrm{n}(\%)$ & $23(7.7)$ & $19(6.3)$ & $11(3.7)$ & $129(43.0)$ \\
\hline
\end{tabular}


Table 2. Fisher exact test regarding the use of social media and the attributes of medical institutions (hospitals).

\begin{tabular}{|c|c|c|c|}
\hline Item and Classification & Not using social media $(\mathrm{N}=222)$ & Using social media $(\mathrm{N}=78)$ & $P$ value \\
\hline Hospital size & & & $<.001$ \\
\hline Small and medium hospitals with $20-199$ beds, n (\%) & $171(77.0)$ & $38(48.7)$ & \\
\hline Large hospitals with more than 200 beds, $n(\%)$ & $51(23.0)$ & $40(51.3)$ & \\
\hline Urban, rural & & & .364 \\
\hline Rural, n (\%) & $18(8.1)$ & $9(11.5)$ & \\
\hline Urban, n (\%) & 204 (91.9) & $69(88.5)$ & \\
\hline Hospital classification & & & .018 \\
\hline General hospital, n (\%) & $108(48.6)$ & $51(65.4)$ & \\
\hline Internal medicine hospital, $\mathrm{n}(\%)$ & 99 (44.6) & $21(26.9)$ & \\
\hline Surgical hospital, n (\%) & $15(6.8)$ & $6(7.7)$ & \\
\hline Established by & & & .073 \\
\hline Individual/nonprofit medical corporations, n (\%) & $182(82.0)$ & $56(71.8)$ & \\
\hline $\begin{array}{l}\text { National/public/social insurance-related organizations, } \\
\mathrm{n}(\%)\end{array}$ & $40(18.0)$ & $22(28.2)$ & \\
\hline Regional Bureau of Health and Welfare & & & .233 \\
\hline Hokkaido, n (\%) & $22(9.9)$ & $4(5.1)$ & \\
\hline Tohoku, n (\%) & $15(6.8)$ & $6(7.7)$ & \\
\hline Kanto-Shinetsu, n (\%) & 48 (21.6) & $28(35.9)$ & \\
\hline Tokai-Hokuriku, n (\%) & $26(11.7)$ & $8(10.3)$ & \\
\hline Kinki, n (\%) & $43(19.4)$ & $10(12.8)$ & \\
\hline Chugoku-Shikoku, n (\%) & $21(9.5)$ & $10(12.8)$ & \\
\hline Shikoku, n (\%) & $9(4.1)$ & $3(3.8)$ & \\
\hline Kyushu, n (\%) & $38(17.1)$ & $9(11.5)$ & \\
\hline Hospital function & & & .004 \\
\hline General hospital, n (\%) & $219(98.6)$ & $71(91.0)$ & \\
\hline $\begin{array}{l}\text { Special functioning hospitals or regional medical care } \\
\text { support hospitals, } \mathrm{n}(\%)\end{array}$ & $3(1.4)$ & $7(9.0)$ & \\
\hline Website & & & .025 \\
\hline Absent, n (\%) & $14(6.3)$ & $0(0.0)$ & \\
\hline Present, n (\%) & $208(93.7)$ & $78(100.0)$ & \\
\hline Beds, median (IQR) & $120.00(69.25-198.75)$ & $220.00(100.50-370.00)$ & $<.001$ \\
\hline Facebook likes, median (IQR) & $\mathrm{N} / \mathrm{A}^{\mathrm{a}}$ & $66.00(19.00-207.00)$ & \\
\hline Twitter followers, median (IQR) & N/A & $7.00(3.00-84.00)$ & \\
\hline
\end{tabular}

${ }^{a}$ NA: not applicable. 
Table 3. Logistic regression analysis of hospital attributes and social media usage (hospitals).

\begin{tabular}{|c|c|c|}
\hline Variable & Odds ratio ( $95 \%$ confidence interval) & $P$ value \\
\hline \multicolumn{3}{|l|}{ Hospital size } \\
\hline Small and medium hospitals with 20 to 199 beds & Reference & $<.001$ \\
\hline Large hospitals with more than 200 beds & $3.25(1.75-6.04)$ & \\
\hline \multicolumn{3}{|l|}{ Hospital classification } \\
\hline General hospital & Reference & \\
\hline Internal medicine hospital & $0.57(0.30-1.09)$ & .088 \\
\hline Surgical hospital & $1.49(0.51-4.32)$ & .46 \\
\hline \multicolumn{3}{|l|}{ Established by } \\
\hline Individual/nonprofit medical corporations & Reference & \\
\hline National/public/social insurance-related organizations & $0.73(0.34-1.56)$ & .41 \\
\hline \multicolumn{3}{|l|}{ Hospital function } \\
\hline General hospital & Reference & \\
\hline $\begin{array}{l}\text { Special functioning hospitals or regional medical care } \\
\text { support hospitals }\end{array}$ & $3.27(0.75-14.40)$ & .12 \\
\hline \multicolumn{3}{|l|}{ Website } \\
\hline Absent & Reference & \\
\hline Present & 9200000.00 (0.00-infinity) & .99 \\
\hline
\end{tabular}

\section{Clinic Accounts}

The number of Facebook and Twitter accounts of clinics was $19 / 300(6.3 \%)$ and $11 / 300(3.7 \%)$, respectively (Table 1). Tables 4 and 5 show the results of Fisher exact test and logistic regression analysis. The Fisher test showed a significant difference in website $(P<.001)$. Logistic regression analysis showed a significant difference in website $(P<.001)$ and specialty (dentistry, $P=.037$ ). Generalized variance inflation factor in logistic regression analysis was 1.01 . 
Table 4. Fisher exact test regarding the use of social media and the attributes of medical institutions (clinics).

\begin{tabular}{|c|c|c|c|}
\hline Item and classification & Not using social media $(\mathrm{N}=277)$ & Using social media $(\mathrm{N}=23)$ & $P$ value \\
\hline Beds & & & .637 \\
\hline Absent, n (\%) & $261(94.2)$ & $21(91.3)$ & \\
\hline Present, n (\%) & $16(5.8)$ & $2(8.7)$ & \\
\hline Urban/Rural & & & .615 \\
\hline Rural, n (\%) & $15(5.4)$ & $0(0.0)$ & \\
\hline Urban, n (\%) & $262(94.6)$ & $23(100.0)$ & \\
\hline Medical/Dental classification & & & .13 \\
\hline Dental clinics, n (\%) & $111(40.1)$ & $13(56.5)$ & \\
\hline Medical clinics, $\mathrm{n}(\%)$ & $166(59.9)$ & $10(43.5)$ & \\
\hline Regional Bureau of Health and Welfare & & & .408 \\
\hline Hokkaido, n (\%) & $7(2.5)$ & $2(8.7)$ & \\
\hline Tohoku, n (\%) & $18(6.5)$ & $0(0.0)$ & \\
\hline Kanto-Shinetsu, n (\%) & $110(39.7)$ & $9(39.1)$ & \\
\hline Tokai-Hokuriku, n (\%) & $36(13.0)$ & $1(4.3)$ & \\
\hline Kinki, n (\%) & $46(16.6)$ & $4(17.4)$ & \\
\hline Chugoku-Shikoku, n (\%) & $15(5.4)$ & $2(8.7)$ & \\
\hline Shikoku, n (\%) & $10(3.6)$ & $1(4.3)$ & \\
\hline Kyushu, n (\%) & $35(12.6)$ & $4(17.4)$ & \\
\hline Established by & & & .736 \\
\hline Individual, $\mathrm{n}(\%)$ & $167(60.3)$ & $13(56.5)$ & \\
\hline Nonprofit medical corporations, $\mathrm{n}(\%)$ & $107(38.6)$ & $10(43.5)$ & \\
\hline $\begin{array}{l}\text { National/public/social insurance related organizations, } \\
\mathrm{n}(\%)\end{array}$ & $3(1.1)$ & $0(0.0)$ & \\
\hline Specialty & & & .185 \\
\hline Internal medicine departments, $\mathrm{n}(\%)$ & $95(34.3)$ & $4(17.4)$ & \\
\hline Surgical departments, $\mathrm{n}(\%)$ & $71(25.6)$ & $6(26.1)$ & \\
\hline Dentistry, n (\%) & $111(40.1)$ & $13(56.5)$ & \\
\hline Website & & & $<.001$ \\
\hline Absent, n (\%) & $169(61.0)$ & $2(8.7)$ & \\
\hline Present, n (\%) & $108(39.0)$ & $21(91.3)$ & \\
\hline Beds, median (IQR) & $0.00(0.00-0.00)$ & $0.00(0.00-0.00)$ & .57 \\
\hline Facebook likes, median (IQR) & $\mathrm{N} / \mathrm{A}^{\mathrm{a}}$ & $69.00(24.50-95.50)$ & \\
\hline Twitter follower, median (IQR) & N/A & $11.00(3.00-23.50)$ & \\
\hline
\end{tabular}

${ }^{\mathrm{a} N A}$ : not applicable. 
Table 5. Logistic regression analysis of hospital attributes and social media usage (clinics).

\begin{tabular}{lll}
\hline Variable & Odds ratio (95\% confidence interval) & $P$ value \\
\hline Website & Reference & $<.001$ \\
Absent & $17.80(4.07-78.20)$ & .25 \\
Present & & .037 \\
Specialty & Reference & \\
$\quad$ Internal medicine departments & $2.20(0.58-8.40)$ & \\
Surgical departments & $3.55(1.08-11.70)$ & \\
$\quad$ Dentistry & &
\end{tabular}

\section{Social Media Policy}

Three hospitals and no clinics disclosed social media usage policies on their website.

\section{Research Question 2}

\section{Number of Comments}

The total number of social media messages disseminated by medical institutions was 8026 from September 16, 2010, to August 4, 2018. Hospitals published 4514 Facebook posts and
2679 tweets, whereas clinics had 503 Facebook posts and 330 tweets. The number of comments we used for content analysis was 1341 hospital Facebook comments and 574 Twitter comments; for clinics, 209 Facebook comments, and 330 Twitter comments. Figure 1 shows the number of monthly comments for the year 2017. For both hospitals and clinics, Facebook posts and tweets all increased in December. In 2017, the annual number of comments for hospitals was 1513 Facebook comments and 262 Twitter comments; for clinics, 121 Facebook comments and 38 Twitter comments. Multimedia Appendix 3 shows examples of contents of hospitals and clinics.

Figure 1. The number of comments for hospitals and clinics in 2017. The number of comments from the clinic was small. The number of comments increased in December at both hospitals and clinics. FB: Facebook; TW: Twitter.

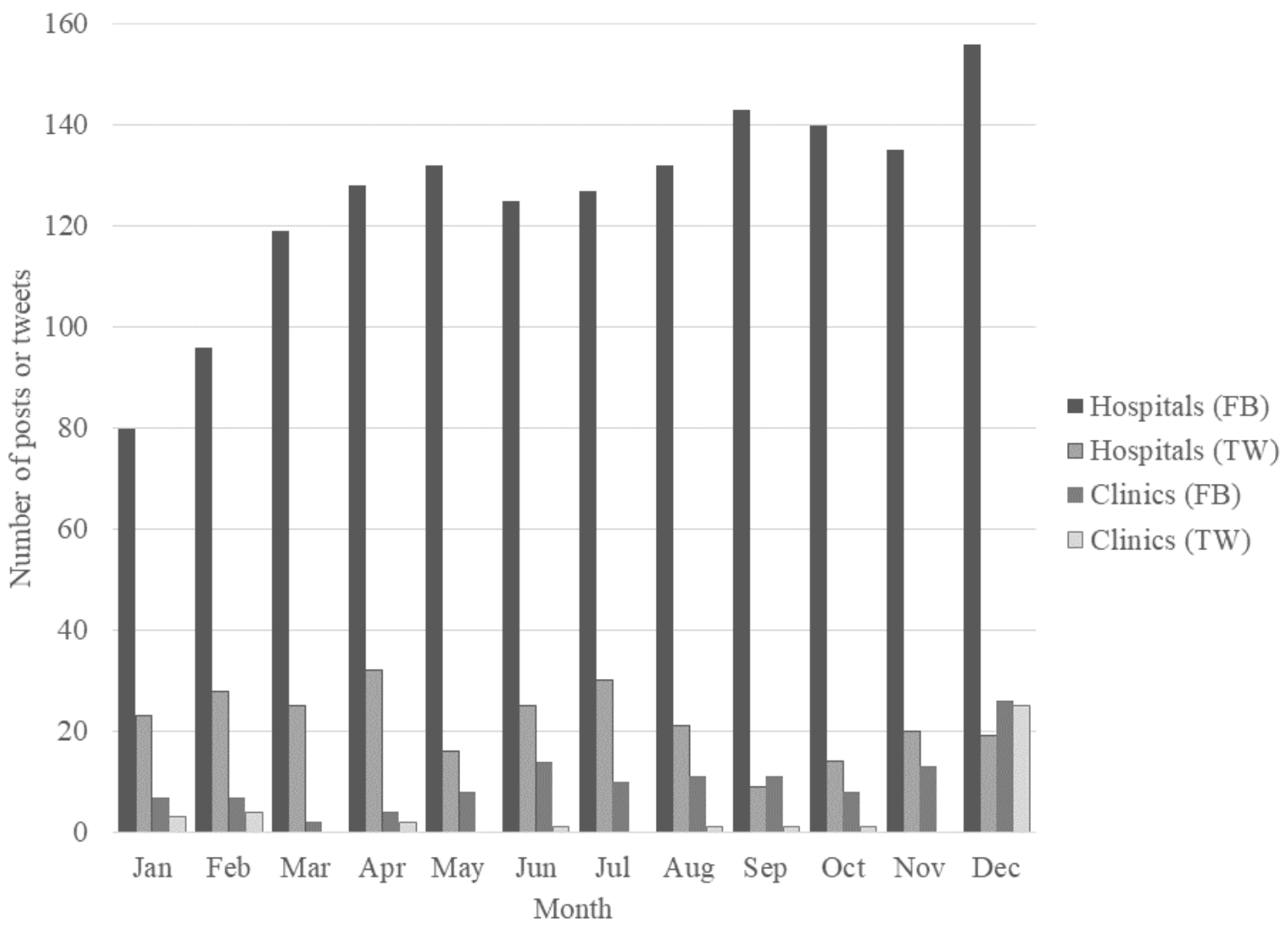




\section{Classification of Contents}

Figures 2 and 3 show the classification of Facebook and Twitter content of hospitals and clinics, respectively. For hospitals and clinics, "Public relations, news announcement" was the highest, accounting for more than $50 \%$ of the content (hospital Facebook content: 53.99\% [724/1341]; hospital Twitter content: $66.6 \%$ [382/574]; clinic Facebook content: 58.4\% [122/209]; clinic
Twitter content: 56.4\% [186/330]). Compared to hospitals, clinics had posted more "Health promotion" tweets on Twitter. For hospitals using Facebook, "Participation in academic meetings, publications" accounted for 24.09\% (323/1341) of the posts, but few in hospitals using Twitter and clinics. Hospitals and clinics disseminated little content related to "Recruitment" on Facebook and Twitter.

Figure 2. Classification and percentage of social media messages (Hospitals). The latest 20 Facebook posts and the latest 100 tweets were manually categorized by content per medical institution. "Participation in academic meetings, publications" accounted for $24.1 \%$ of the Facebook posts.

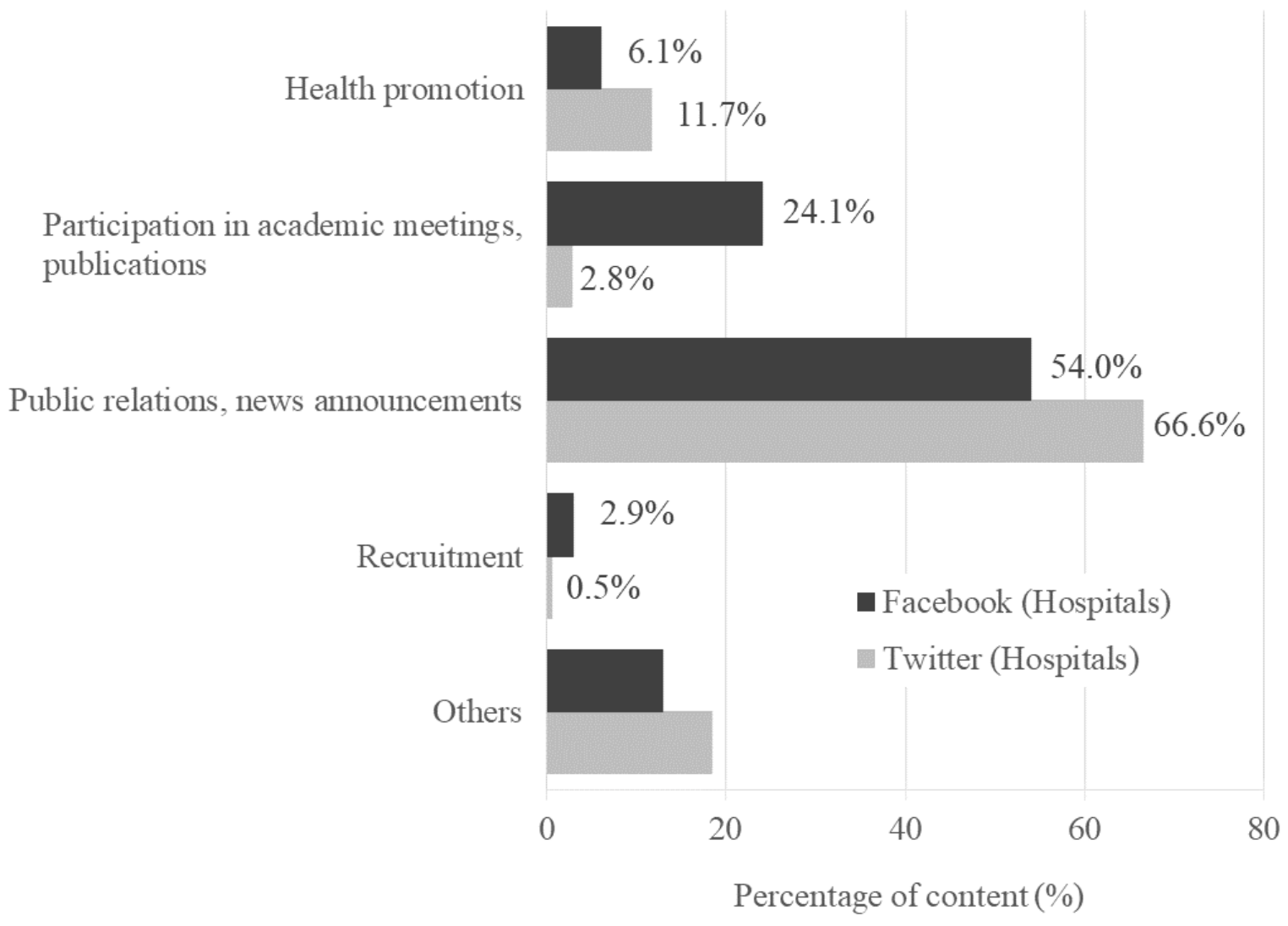


Figure 3. Classification and percentage of social media messages (clinics). The latest 20 Facebook posts and the latest 100 tweets were manually categorized by content per medical institution. Higher percentage of "Health promotion" compared to hospitals.

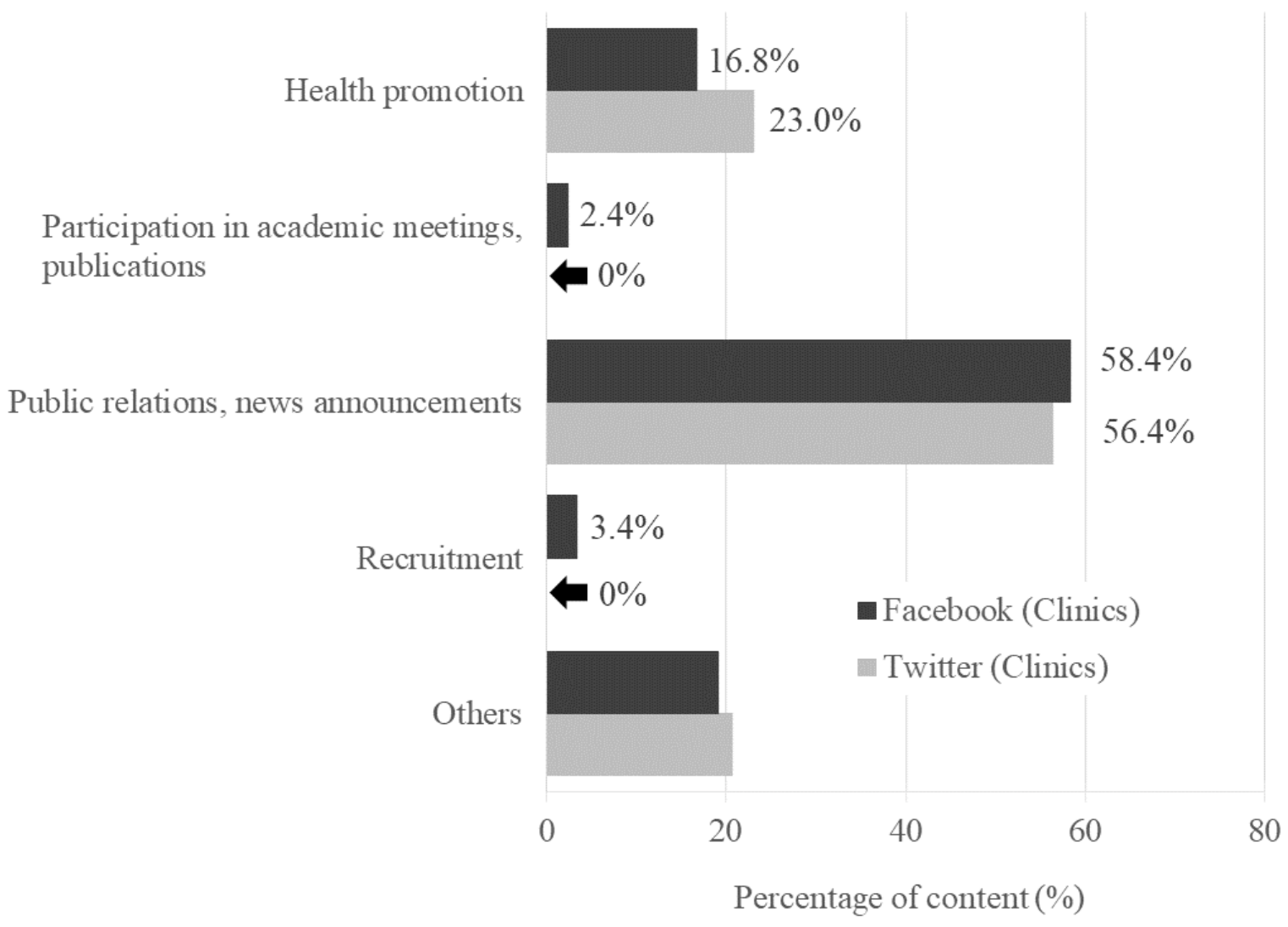

\section{Term Frequency and Co-occurrence Network}

The results of text mining are shown in Figures 4 and 5, and Multimedia Appendix 4. On the Facebook accounts of hospitals, more words related to conference presentations appeared than others. The frequency was 815 times for "academic meeting,"
746 times for "presentation," and 635 times for "research," thus, forming a co-occurrence network. On hospital Twitter accounts, "influenza" formed a co-occurrence network. At clinics, there were many announcements about leave of absence on both Facebook and Twitter. The number of occurrences of "closed" was 158 and 73, respectively, on Facebook and Twitter. 
Figure 4. A co-occurrence network for the hospitals in this study. Words in the same subgraph are connected by a solid line. When co-occurring with words in other subgraphs, they are connected by a broken line. Information related to nursing care, community-based health care, academic meeting, and lectures was posted on Facebook. On Twitter, there were tweets about a fun party at a hospital and tweets about updating the blog of hospital B.

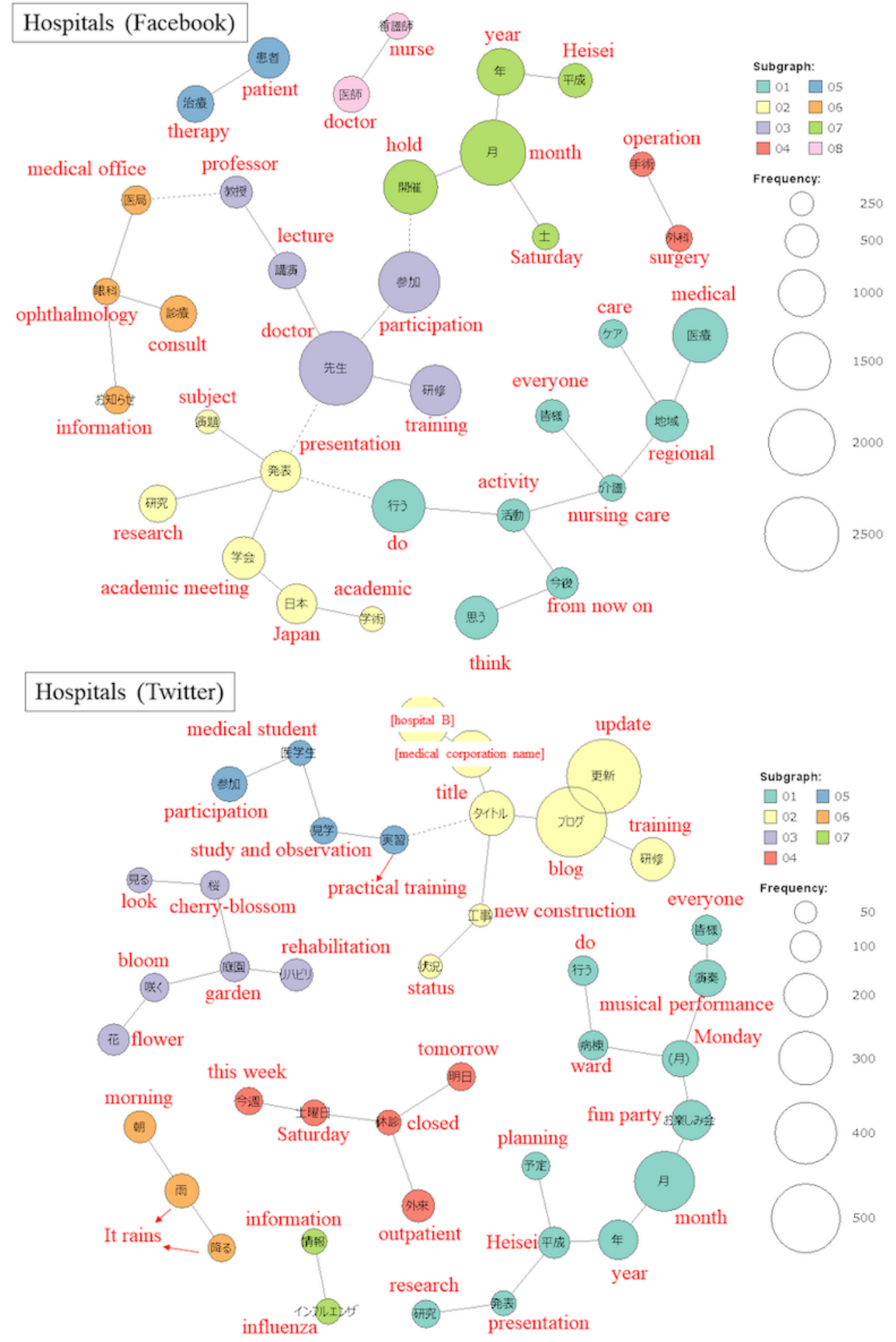


Figure 5. A co-occurrence network for the clinics in this study. Words in the same subgraph are connected by a solid line. When co-occurring with words in other subgraphs, they are connected by a broken line. Single words that do not belong to any subgraph are shown in white. On Facebook, a clinic was raising awareness about nutrition and omega fatty acids. On Twitter, there were tweets about free counseling on orthodontics.
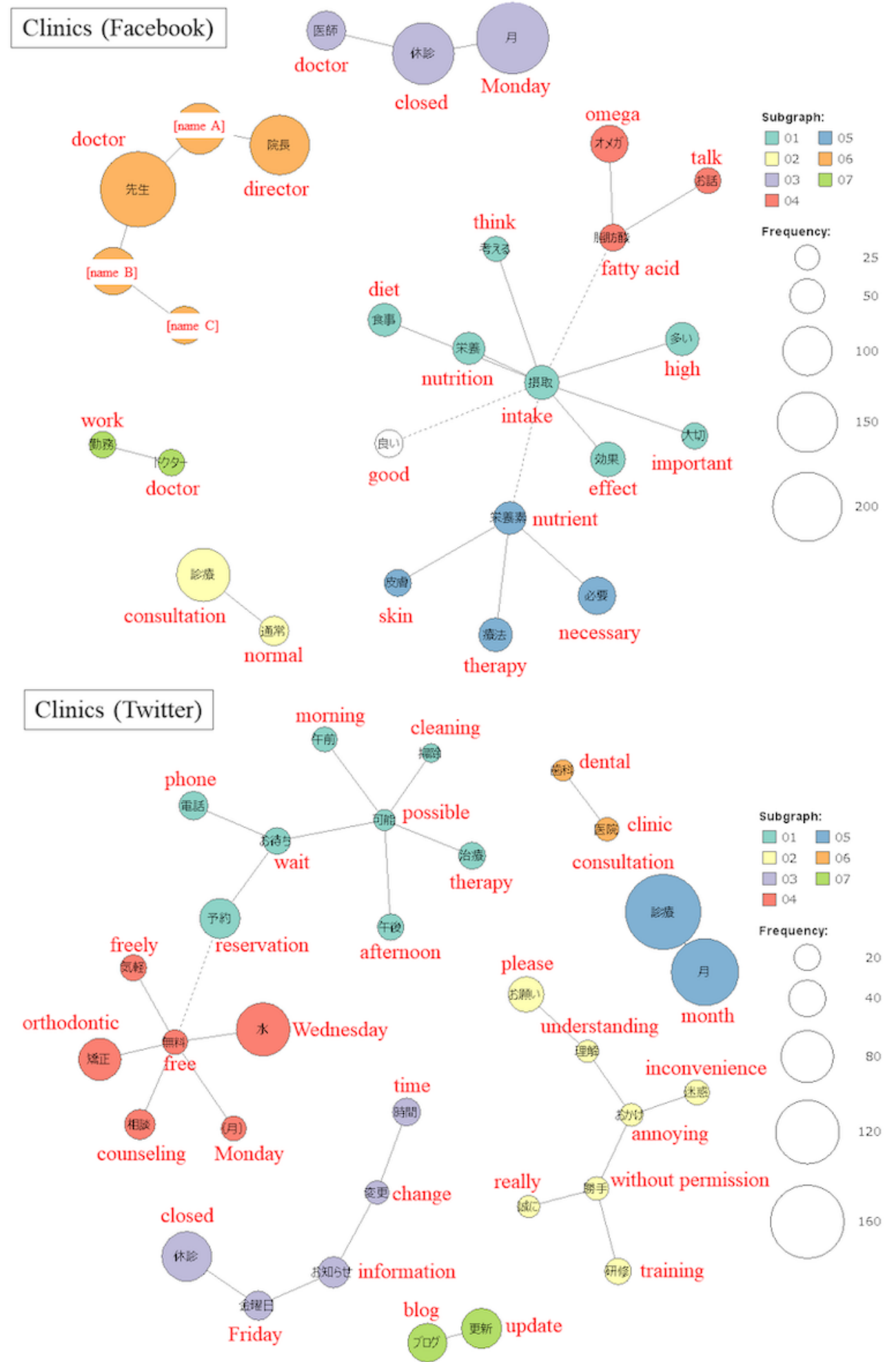

\section{Research Question 3}

Table 6 shows the comparison between social media contents and guidelines. Content that could conflict with the guidelines and the percentage of total content by hospitals using Facebook

and Twitter were $16(1.19 \%, 16 / 1341)$ and $6(1.0 \%, 6 / 574)$, respectively. In clinics, 8 Facebook posts $(3.8 \%, 8 / 209)$ and 15 tweets $(4.5 \%, 15 / 330)$ could conflict medical advertising guidelines. Multimedia Appendix 5 shows examples of this content. 
Table 6. Number of messages that may violate medical advertising guidelines and professional ethics.

\begin{tabular}{|c|c|c|c|c|c|}
\hline \multirow[t]{2}{*}{ Evaluation items $^{\mathrm{a}}$} & \multirow[t]{2}{*}{ Applicable part of the guidelines ${ }^{b}$} & \multicolumn{2}{|l|}{ Hospitals } & \multicolumn{2}{|l|}{ Clinics } \\
\hline & & Facebook & Twitter & Facebook & Twitter \\
\hline Introduction in media & $\begin{array}{l}\text { By quoting or publishing articles in newspa- } \\
\text { pers and magazines, discourses, theories, } \\
\text { and experiences of doctors and scholars }\end{array}$ & 12 & 4 & 4 & 0 \\
\hline Messages on safety & Misleading advertising & 0 & 0 & 1 & 0 \\
\hline $\begin{array}{l}\text { Invitation by matters not related to provid- } \\
\text { ing medical care }\end{array}$ & Advertising that impairs dignity & 0 & 0 & 0 & 5 \\
\hline Emphasis on cost & Advertising that impairs dignity & 0 & 2 & 1 & 10 \\
\hline Medical department name & Not included in advertisable items & 0 & 0 & 0 & 0 \\
\hline Professional qualification & Not included in advertisable items & 1 & 0 & 0 & 0 \\
\hline Regulations by other laws and regulations & $\begin{array}{l}\text { Advertising prohibited by other laws or } \\
\text { other advertising guidelines }\end{array}$ & 1 & 0 & 0 & 0 \\
\hline $\begin{array}{l}\text { Messages suggesting the superiority of the } \\
\text { medical institution by comparison, exagger- } \\
\text { ated expressions of facility size, staffing, or } \\
\text { medical provision }\end{array}$ & $\begin{array}{l}\text { Advertising that implies their superiority } \\
\text { by comparison/Misleading advertising }\end{array}$ & 0 & 0 & 2 & 0 \\
\hline Ethical issues & $\begin{array}{l}\text { Refer to the "Doctors' Professional Ethics } \\
\text { Guidelines" issued by the Japan Medical } \\
\text { Association }\end{array}$ & 2 & 0 & 0 & 0 \\
\hline
\end{tabular}

${ }^{\mathrm{a}, \mathrm{b}}$ Refer to Multimedia Appendix 1.

\section{Discussion}

\section{Preliminary Findings}

In this study, 300 hospitals and clinics, respectively, were sampled and classified according to social media accounts and their contents. In Japan, fewer medical institutions use social media than those in the United States and Western Europe. In addition, medical institutions using social media frequently used them as part of public relations activities. Some included messages that may violate medical advertising guidelines. To protect the reputation of medical institutions, it is considered necessary to formulate social media policies.

\section{Social Media Accounts}

In Japan, social media were rarely used by medical institutions, and it was considered that websites were mainly used for the dissemination of health information by medical institutions (Table 1). An online survey on health awareness among 3000 people showed that less than $5 \%$ used social networking sites as health information sources [41]. For this reason, even if a medical institution creates a social media account, only few users possibly refer to social media information from medical institutions. Because of a limited number of users, the number of "likes" and "followers" would not increase, and it would be difficult for medical institutions to ascertain the influence of using social media. As a result, medical institutions will interrupt the use of social media. In the United States, social media are an important source of information for using health information on the internet. According to a survey conducted in the United States in 2011, about one-fifth of approximately 23,000 respondents said that social media were the source of health information. In addition, one-third of respondents reported that social media are a reliable information source [42]. This viewpoint difference about social media between Japan and the United States may be reflected in the differences in social media utilization rates by medical institutions.

\section{Social Media Utilization and Benefits}

Social media have been used to maintain or improve peer-to-peer and clinician-to-patient communication, promote institutional branding, and improve the speed of interaction between and across different health care stakeholders in the health care field [43]. Patients may perceive that hospitals with social media activity are likely to offer advanced technologies and cutting-edge therapies [6].

In Japan, more than $50 \%$ of the social media comments sent by medical institutions were related to public relations activities. About a quarter of Facebook posts by hospitals were related to participation in academic conferences and the publication of academic papers (Figure 2). In text mining the Facebook accounts of hospitals, the frequency of "academic meeting" and "presentation" was high (Multimedia Appendix 4). Subgraphs related to conference presentations also appeared in the co-occurrence network (Figure 4). In particular, hospitals may have used social media to disseminate academic information. Additionally, an apology posted on Facebook by a hospital regarding the emergency discharge (quenching) of helium gas from a magnetic resonance imaging system was found (Multimedia Appendix 3). In this context, several reports have claimed that social media are a useful communication tool in emergency situations, such as disasters and accidents [44-51]. Further, social media may be useful when we want to share information urgently, because they have the advantage of immediacy compared to conventional media. 
Social media have often been used for the purpose of health promotion and health education [5], and such health information may be used to improve public health as well. However, only a few medical knowledge and health information messages are disseminated by medical institutions in Japan. It may be even better to consider the season when health information is disseminated, as the number of monthly comments increased in December (Figure 1), a possible reason being the increased number of comments about Christmas as well as the year-end and New Year holidays. However, when medical institutions disseminate information on social media, it may be good to raise awareness not only about annual events but also about seasonal diseases. In fact, the spread of awareness on influenza vaccination using social media is common [52]. In addition, information on pollen allergy is provided using a mobile app [53].

Social media use by medical institutions involves mostly one-way communication, and few medical institutions respond to inquiries from the general public or patients via social media [8]. However, two-way communication with the general public and patients may meet patient needs that cannot be met through daily medical care and may thus help improve the provision of care $[54,55]$.

\section{Risks and Problems in Using Social Media}

There are some problems with medical institutions using social media. These include concerns about patient privacy breaches, issues with the reliability and poor quality of information, and the obscuring of boundaries between health care professionals and patients $[5,56]$.

When medical institutions disseminate information on social media, great care should be taken not to breach patient privacy as seemingly innocent comments can do so [57]. Even if the post does not contain a specific name, it may be possible to identify the patient by indirect information such as the name of the town where the patient lives, gender, or disease name [57]. Thus, medical institutions should be cautious when posting on social media, as these privacy breaches may occur unintentionally.

It is often difficult to tell who wrote health information on social media, which raises concerns regarding its accuracy and reliability [56]. Additionally, if medical institutions use social media, it will be necessary to clarify the boundaries between health care professionals and patients. Few doctors and medical institutions respond to "friend" requests from patients [56], but it is better to prescribe what to do when receiving "friend requests" in the social media policy in advance.

Moreover, when a medical institution uses social media, it may be necessary to create a social media policy not only to clarify the purpose of social media use but also to protect its reputation [56,58-60]. In this study, only 3 medical institutions disclosed their social media policies on their website. Thus, many medical institutions might not develop social media policies. In this context, damage to reputation and breach of patient privacy are matters of concern when medical institutions use social media [58]. Consequently, medical institutions should have clear

objectives [59] and develop social media policies to avoid these risks.

\section{Comparison With the Guidelines}

In this survey, no content that violated patient privacy was extracted. However, some contents that could violate the guidelines were extracted. Of the hospital's Facebook posts, $0.89 \%$ (12/1341) commented on being featured in the media. According to medical advertising guidelines, coverage announcements are also considered as advertising, and they are essentially restricted. Therefore, when sending information through social media, it would be necessary to refrain from commenting on whether their facility and staff are featured in newspapers, magazines, and other media. There was also a hospital Facebook account that sent company advertisements directly without disclosing conflicts of interest. This is considered ethically problematic. The Doctor's Professional Ethics Guidelines stipulate that the relationship with medical providers should be appropriate [32]. In the website guidelines by the Japan Medical Association, "advertising by external sponsors" is listed as ineligible content [31]. Similarly, there are provisions regarding conflicts of interest in overseas guidelines; the British Medical Association social media usage guidelines require disclosure of conflicts of interest when doctors and medical students post information online [61].

Some clinics posted tweets emphasizing costs and matters not related to medical provision. An example is the toothbrush gift campaign when visiting the dental clinic, as well as discount campaigns such as medical checkups and whitening. In general, when a company uses a social medium for promotional purposes, coupons are often issued and discounts are announced on the social medium $[62,63]$. Therefore, if a medical institution uses social media like a company, it may be easy to disseminate messages on examinations and treatment fees and discounts. However, according to medical advertising guidelines, advertising that emphasizes costs is considered "Advertising that impairs dignity," and such messages should not be disseminated. By disseminating such inappropriate messages, medical institutions not only receive a reprimand from health authorities but may also lose their good reputation.

The government should probably respond to messages on social media. In this study, referring to medical advertisement guidelines and the literature, we determined whether social media contents disseminated by medical institutions violated the guidelines. For some contents, it was difficult to determine whether they meet the guidelines. Governments might need to articulate the criteria for determining whether their contents are appropriate or inappropriate. The MHLW's internet patrol and public notification regarding medical institutions' websites are currently in execution $[64,65]$. In addition, it may be necessary to strengthen checks on inappropriate social media cases.

\section{Limitations}

\section{Sampling Methods}

In this study, we randomly assigned a number to the list of medical institutions in Japan and extracted 300 small samples for each hospital and clinic. Compared to the actual number of medical institutions, these samples showed no statistically 
significant difference in the number of medical institutions by region, as presented in this study. In this study, regional bias may be possible, but it may be limited. However, the samples may not be representative of all Japanese medical institutions. These samples may be biased when examined in detail with prefectures and cities. Additionally, the characteristics and attributes of medical institutions may be biased. For a detailed study of social media usage in Japanese medical institutions in the future, it may be necessary to increase the sample size and reduce the confidence interval width. In addition, sampling methods such as stratified random sampling, cluster sampling, and multistage sampling should be used to obtain more representative samples [66].

\section{Content Analysis}

In this study, the classification of contents and the comparison with the medical advertising guidelines were made based on the consensus of 3 researchers. However, it did not preclude personal subjectivity; classification and comparison may be inconsistent, and objective evaluation will be necessary in future research. Further, measurement of intercoder reliability, which is fundamental and important in content analysis [67], is required for an objective evaluation. In addition, a thematic analysis approach such as topic modeling is required for objective categorization $[68,69]$.

\section{Factors Affecting Social Media Use in Medical Institutions}

Regarding the use of social media by medical institutions, this study does not clarify the factors that led to the use of social media or the reasons why they were not used. Thus, the application of the unified theory of acceptance and use of technology and technology acceptance model may be necessary to examine the factors behind the use of social media in medical institutions [70].

\section{Other Social Media}

In this study, the target social media were limited to Facebook and Twitter. In future studies, it will be necessary to investigate the use of other platforms, such as blogs, wikis, LINE, and Instagram accounts of medical institutions. Blogs have been used since as early as 2004, and Wikipedia is often used in the medical community [43]. However, there are no reports of their usage at medical institutions in Japan, and the details remain unknown. LINE was developed in Japan [71], and its usage rate in Japan is high. According to a Ministry of Internal Affairs and Communications survey of 1500 people in 2016, Facebook usage was $32.3 \%$ and Twitter usage was $27.5 \%$, whereas LINE usage was $67.0 \%$, the highest [72]. In fact, it has been reported in a newspaper that a medical institution already uses LINE [73]. If medical institutions use LINE, messages pertaining to public relations and awareness activities may be more effectively distributed than via Facebook and Twitter. Instagram is a photo-sharing site that has been rapidly growing by the increasing number of users in recent years [74]. Medical institutions may be able to promote public relations activities by posting visually appealing images of them on Instagram. However, images that may violate medical advertising guidelines may be posted.

\section{Lack of Cosmetic Surgery Clinics in the Sample}

In this study, we investigated the actual use of social media by medical institutions throughout Japan but did not include cosmetic surgery clinics in the sample. Cosmetic surgery clinics might disseminate more advertisements than other specialties because many cosmetic surgeries are performed as part of free medical care, and the ratio of content may differ from this survey.

\section{Necessity of a Longitudinal Study}

The data presented in this study are cross-sectional at the time of the survey. Previous studies have shown that the use of social media by medical institutions has changed over time $[7,75]$. Therefore, in Japan, it will be necessary to observe social media usage by medical institutions over time.

\section{Conclusions}

Social media usage by Japanese medical institutions is lower than that in the United States and Western European countries, and these media are mainly used for messages related to public relations. Some social media contents posted by medical institutions could conflict with medical advertising guidelines. In addition, few medical institutions have established social media policies. Due to deviations in usage rates from overseas and the characteristics of social media, it is necessary to consider social media other than Facebook and Twitter. This study may serve as a reference for medical institutions to guide social media usage and help improve medical website advertising in Japan.

\section{Acknowledgments}

This work was supported by JSPS KAKENHI (Grant Number JP18H00507). We thank Editage for English language editing.

\section{Conflicts of Interest}

None declared.

\section{Multimedia Appendix 1}

Criteria for comparing social media content and guidelines, professional ethics.

[DOCX File, 18 KB-Multimedia Appendix 1] 


\section{Multimedia Appendix 2}

Percentage of sample medical institutions by each region and percentage of actual medical institutions.

[DOCX File, $21 \mathrm{~KB}-$ Multimedia Appendix 2]

\section{Multimedia Appendix 3}

Examples of social media contents.

[DOCX File, 18 KB-Multimedia Appendix 3]

\section{Multimedia Appendix 4}

Number of frequencies of words in Facebook posts and tweets by hospitals and clinics top 50.

[DOCX File, 33 KB-Multimedia Appendix 4]

\section{Multimedia Appendix 5}

Examples of messages that may violate medical advertising guidelines and professional ethics.

[DOCX File, 17 KB-Multimedia Appendix 5]

\section{References}

1. Kemp S. Digital 2020: Global Digital Overview. 2020. URL: https://datareportal.com/reports/ digital-2020-global-digital-overview [accessed 2020-10-20]

2. Statistita. Number of monthly active Facebook users worldwide as of 2nd quarter 2020 (in millions). URL: https://www. statista.com/statistics/264810/number-of-monthly-active-facebook-users-worldwide/ [accessed 2020-10-19]

3. Statistita. Number of monthly active Twitter users worldwide from 1st quarter 2010 to 1st quarter 2019 (in millions). URL: https://www.statista.com/statistics/282087/number-of-monthly-active-twitter-users/ [accessed 2020-10-19]

4. Bugajski M. Japan's Top Social Media Networks for 2020. URL: https://www.humblebunny.com/ japans-top-social-media-networks/ [accessed 2020-10-19]

5. Moorhead SA, Hazlett DE, Harrison L, Carroll JK, Irwin A, Hoving C. A new dimension of health care: systematic review of the uses, benefits, and limitations of social media for health communication. J Med Internet Res 2013;15(4):e85 [FREE Full text] [doi: 10.2196/jmir.1933] [Medline: 23615206]

6. Griffis HM, Kilaru AS, Werner RM, Asch DA, Hershey JC, Hill S, et al. Use of social media across US hospitals: descriptive analysis of adoption and utilization. J Med Internet Res 2014;16(11):e264 [FREE Full text] [doi: 10.2196/jmir.3758] [Medline: 25431831]

7. Van de Belt TH, Berben SAA, Samsom M, Engelen LJLPG, Schoonhoven L. Use of social media by Western European hospitals: longitudinal study. J Med Internet Res 2012;14(3):e61 [FREE Full text] [doi: 10.2196/jmir.1992] [Medline: 22549016]

8. Thaker SI, Nowacki AS, Mehta NB, Edwards AR. How U.S. hospitals use social media. Ann Intern Med 2011 May 17;154(10):707-708. [doi: 10.7326/0003-4819-154-10-201105170-00021] [Medline: 21576547]

9. Suby C. Social Media in Health Care: Benefits, Concerns, and Guidelines for Use. Creat Nurs 2013 Jan 01;19(3):140-147. [doi: 10.1891/1078-4535.19.3.140] [Medline: 24400468]

10. Reissis D, Shiatis A, Nikkhah D. Advertising on Social Media: The Plastic Surgeon's Prerogative. Aesthet Surg J 2017 Jan;37(1):NP1-NP2. [doi: 10.1093/asj/sjw174] [Medline: 27771608]

11. Health and Global Policy Institute. Overview of Major Legislation (The eighth revision to the $1948 \mathrm{Medical}$ Care Act). URL: http://japanhpn.org/en/section-1-3/ [accessed 2020-10-19]

12. Sei S. Notes on websites due to Medical Care Act revisions (viewpoints for responding to Medical Care Act revisions and creating homepages) [In Japanese]. Byoin-Rashinban 2017/10/15 2017;8(112):18-22.

13. Ministry of Health, Labour and Welfare. Guidelines (Medical Advertising Guidelines) for Advertising for Medical and Dental Services , Hospitals and Clinics [In Japanese]. 2018. URL: https://www.mhlw.go.jp/file/ 06-Seisakujouhou-10800000-Iseikyoku/0000206548.pdf [accessed 2020-10-19]

14. Okamoto E. Current status of receipt online and outlook for national database [In Japanese]. 2009 Mar 3. URL: http://www. resept.com/yakujiexpert.pdf [accessed 2020-10-19]

15. Ehara A. The shortest distance between the center of population of each municipality nationwide and the core pediatrics and regional pediatric centers [In Japanese]. The Journal of the Japan Pediatric Society 2016;120(10):1508-1513.

16. Yahoo! Japan. News of yahoo! Health care End [In Japanese]. URL: https://medical.yahoo.co.jp/ [accessed 2018-04-01] [WebCite Cache ID 6yLmbU0PN]

17. Kondo A, Shigeoka H. Effects of universal health insurance on health care utilization, and supply-side responses: Evidence from Japan. Journal of Public Economics 2013 Mar;99:1-23 [FREE Full text] [doi: 10.1016/j.jpubeco.2012.12.004] 
18. Ikegami N, Campbell JC. Health care reform in Japan: the virtues of muddling through. Health Aff (Millwood) 1999;18(3):56-75. [doi: $\underline{10.1377 / \text { hlthaff.18.3.56] [Medline: } 10388203 \text { ] }}$

19. Ito A. Logic, ethical problems, and status of consensus concerning free access to health care insurance system [In Japanese]. Policy and Practice Studies 2018;4(1):125-137.

20. Chugoku-Shikoku Regional Bureau of Health and Welfare. List of insurance medical institutions within the jurisdiction of Chugoku-Shikoku Regional Bureau of Health and Welfare [In Japanese]. URL: https://kouseikyoku.mhlw.go.jp/ chugokushikoku/chousaka/iryoukikanshitei.html [accessed 2020-10-19]

21. Hokkaido Regional Bureau of Health and Welfare. List of insurance medical institutions within the jurisdiction of Hokkaido Regional Bureau of Health and Welfare [In Japanese]. URL: https://kouseikyoku.mhlw.go.jp/hokkaido/gyomu/gyomu/ hoken_kikan/code_ichiran.html [accessed 2020-10-19]

22. Kanto-Shinetsu Regional Bureau of Health and Welfare. List of insurance medical institutions within the jurisdiction of Kanto-Shinetsu Regional Bureau of Health and Welfare [In Japanese]. URL: https://kouseikyoku.mhlw.go.jp/kantoshinetsu/ chousa/shitei.html [accessed 2020-10-19]

23. Kinki Regional Bureau of Health and Welfare. List of insurance medical institutions within the jurisdiction of Kinki Regional Bureau of Health and Welfare [In Japanese]. URL: https://kouseikyoku.mhlw.go.jp/kinki/tyousa/shinkishitei.html [accessed 2020-10-19]

24. Kyushu Regional Bureau of Health and Welfare. List of insurance medical institutions within the jurisdiction of Kyushu Regional Bureau of Health and Welfare [In Japanese]. URL: https://kouseikyoku.mhlw.go.jp/kyushu/gyomu/gyomu/ hoken_kikan/index.html [accessed 2020-10-19]

25. Shikoku Regional Bureau of Health and Welfare. List of insurance medical institutions within the jurisdiction of Shikoku Regional Bureau of Health and Welfare [In Japanese]. URL: https://kouseikyoku.mhlw.go.jp/shikoku/gyomu/gyomu/ hoken_kikan/shitei/index.html [accessed 2020-10-19]

26. Tohoku Regional Bureau of Health and Welfare. List of insurance medical institutions within the jurisdiction of Tohoku Regional Bureau of Health and Welfare [In Japanese]. URL: https://kouseikyoku.mhlw.go.jp/tohoku/gyomu/gyomu/ hoken_kikan/itiran.html [accessed 2020-10-19]

27. Tokai-Hokuriku Regional Bureau of Health and Welfare. List of insurance medical institutions within the jurisdiction of Tokai-Hokuriku Regional Bureau of Health and Welfare [In Japanese]. URL: https://kouseikyoku.mhlw.go.jp/tokaihokuriku/ gyomu/gyomu/hoken_kikan/shitei.html [accessed 2020-10-19]

28. The Social Media Research Foundation. NodeXL Graph Gallery: About NodeXL. URL: http://nodexlgraphgallery.org/ Pages/AboutNodeXL.aspx [accessed 2020-10-19]

29. Richter JP, Muhlestein DB, Wilks CEA. Social media: how hospitals use it, and opportunities for future use. J Healthc Manag 2014;59(6):447-460. [Medline: 25647968]

30. Gomes C, Coustasse A. Tweeting and Treating: How Hospitals Use Twitter to Improve Care. Health Care Manag (Frederick) 2015;34(3):203-214. [doi: 10.1097/HCM.0000000000000063] [Medline: 26217995]

31. Japan Medical Association. The way medical facility websites should be -Guidelines for providing member medical facilities and medical information- (2008 March revised edition) [In Japanese]. 2008 Mar. URL: http://dl.med.or.jp/dl-med/nichikara/ hp_guide.pdf [accessed 2020-10-19]

32. Japan Medical Association. Doctor's Professional Ethics Guidelines Third edition October 2016 [In Japanese]. 2016. URL: http://dl.med.or.jp/dl-med/teireikaiken/20161012 2.pdf [accessed 2020-10-19]

33. Ohba H. Research on the Information Provision of the Aesthetic Medical Service in the Aesthetic Medical Institutions' Websites [In Japanese]. Journal of the Japan Association for Medical Informatics 2016;36(2):79-84.

34. Higuchi K. A Two-Step Approach to Quantitative Content Analysis: KH Coder Tutorial Using Anne of Green Gables (Part I). Ritsumeikan Social Science Review 2016;52(3):77-91.

35. Higuchi K. A Two-Step Approach to Quantitative Content Analysis: KH Coder Tutorial Using Anne of Green Gables (Part II). Ritsumeikan Social Science Review 2017;53(1):137-147.

36. Higuchi K. KH Coder Index Page. URL: https://khcoder.net/en/ [accessed 2020-10-19]

37. Higuchi K. KH Coder 3 Reference Manual. URL: https://khcoder.net/en/manual en v3.pdf [accessed 2020-10-19]

38. Tsuya A, Sugawara Y, Tanaka A, Narimatsu H. Do cancer patients tweet? Examining the twitter use of cancer patients in Japan. J Med Internet Res 2014 May 27;16(5):e137 [FREE Full text] [doi: 10.2196/jmir.3298] [Medline: 24867458]

39. Ministry of Health, Labour and Welfare. Overview of medical facility (static / dynamic) surveys and hospital reports 2017 [In Japanese]. 2017. URL: https://www.mhlw.go.jp/toukei/saikin/hw/iryosd/17/ [accessed 2020-10-19]

40. Kanda Y. Investigation of the freely available easy-to-use software 'EZR' for medical statistics. Bone Marrow Transplant 2013 Mar;48(3):452-458 [FREE Full text] [doi: 10.1038/bmt.2012.244] [Medline: 23208313]

41. MSD K.K. "Health and Medical Awareness Survey" [In Japanese]. 2017. URL: http://www.msd.co.jp/static/pdf/ corporate_20171127_2.pdf [accessed 2020-10-17]

42. National Research Corporation. 1 in 5 Americans Use Social Media for Health Care Information. 2011. URL: http://hcmg. nationalresearch.com/public/News.aspx?ID=9 [accessed 2019-01-08] [WebCite Cache ID 72AhcT717]

43. Grajales FJ, Sheps S, Ho K, Novak-Lauscher H, Eysenbach G. Social media: a review and tutorial of applications in medicine and health care. J Med Internet Res 2014 Feb 11;16(2):e13 [FREE Full text] [doi: 10.2196/jmir.2912] [Medline: 24518354] 
44. Haruna N, Ako K. Special Issue: Medical Care Connected with Social Media [In Japanese]. Nikkei Medical 2011;40(7):58-74.

45. Alexander DE. Social media in disaster risk reduction and crisis management. Sci Eng Ethics 2014 Sep;20(3):717-733. [doi: 10.1007/s11948-013-9502-z] [Medline: 24306994]

46. Huang C, Chan E, Hyder AA. Web 2.0 and internet social networking: a new tool for disaster management? Lessons from Taiwan. BMC Med Inform Decis Mak 2010 Oct 06;10:57 [FREE Full text] [doi: 10.1186/1472-6947-10-57] [Medline: 20925944]

47. Acar A, Muraki Y. Twitter for crisis communication: lessons learned from Japan's tsunami disaster. IJWBC 2011;7(3):392. [doi: 10.1504/ijwbc.2011.041206]

48. Vieweg S, Hughes A, Starbird K, Palen L. Microblogging During Two Natural Hazards Events: What Twitter May Contribute to Situational Awareness. 2010 Presented at: CHI '10: Proceedings of the SIGCHI Conference on Human Factors in Computing Systems; April, 2010; Atlanta Georgia USA URL: https://doi.org/10.1145/1753326.1753486

49. Houston JB, Hawthorne J, Perreault MF, Park EH, Goldstein Hode M, Halliwell MR, et al. Social media and disasters: a functional framework for social media use in disaster planning, response, and research. Disasters 2015 Jan 22;39(1):1-22. [doi: 10.1111/disa.12092] [Medline: 25243593]

50. Côté E, Hearn R. The medical response to the Boston Marathon bombings: an analysis of social media commentary and professional opinion. Perspect Public Health 2016 Nov;136(6):339-344. [doi: 10.1177/1757913916644480] [Medline: 27161388]

51. Cassa C, Chunara R, Mandl K, Brownstein JS. Twitter as a sentinel in emergency situations: lessons from the Boston marathon explosions. PLoS Curr 2013 Jul 02;5 [FREE Full text] [doi: 10.1371/currents.dis.ad70cd1c8bc585e9470046cde334ee4b] [Medline: 23852273]

52. Bekkat-Berkani R, Romano-Mazzotti L. Understanding the unique characteristics of seasonal influenza illness to improve vaccine uptake in the US. Vaccine 2018 Nov 19;36(48):7276-7285 [FREE Full text] [doi: 10.1016/j.vaccine.2018.10.027] [Medline: $\underline{30366802]}$

53. Kmenta M, Zetter R, Berger U, Bastl K. Pollen information consumption as an indicator of pollen allergy burden. Wien Klin Wochenschr 2016 Jan;128(1-2):59-67. [doi: 10.1007/s00508-015-0855-y] [Medline: 26373744]

54. Sugawara Y, Narimatsu H, Tsuya A, Tanaka A, Fukao A. Medical Institutions and Twitter: A Novel Tool for Public Communication in Japan. JMIR Public Health Surveill 2016;2(1):e19 [FREE Full text] [doi: 10.2196/publichealth.4831] [Medline: 27227154]

55. Greaves F, Laverty AA, Cano DR, Moilanen K, Pulman S, Darzi A, et al. Tweets about hospital quality: a mixed methods study. BMJ Qual Saf 2014 Oct;23(10):838-846 [FREE Full text] [doi: 10.1136/bmjqs-2014-002875] [Medline: 24748372]

56. Ventola CL. Social media and health care professionals: benefits, risks, and best practices. P T 2014 Jul;39(7):491-520 [FREE Full text] [Medline: 25083128]

57. Schumacher KR, Lee JM, Pasquali SK. Social media in paediatric heart disease: professional use and opportunities to improve cardiac care. Cardiol Young 2015 Dec;25(8):1584-1589. [doi: 10.1017/S1047951115002292] [Medline: 26675608]

58. Cain J. Social media in health care: the case for organizational policy and employee education. Am J Health Syst Pharm 2011 Jun 01;68(11):1036-1040. [doi: 10.2146/ajhp100589] [Medline: 21593233]

59. Gagnon K, Sabus C. Professionalism in a digital age: opportunities and considerations for using social media in health care. Phys Ther 2015 Mar;95(3):406-414. [doi: 10.2522/ptj.20130227] [Medline: 24903111]

60. Pillow MT, Hopson L, Bond M, Cabrera D, Patterson L, Pearson D, Council of Residency Directors Social Media Task Force. Social media guidelines and best practices: recommendations from the Council of Residency Directors Social Media Task Force. West J Emerg Med 2014 Feb;15(1):26-30 [FREE Full text] [doi: 10.5811/westjem.2013.7.14945] [Medline: $\underline{24578765]}$

61. British Medical Association. Using social media: practical and ethical guidance for doctors and medical students. 2011. URL: http://www.medschools.ac.uk/SiteCollectionDocuments/social media guidance may2011.pdf [accessed 2015-11-24] [WebCite Cache ID 6dH18d3p1]

62. Ministry of Economy, Trade and Industry. METI Compiled a Survey Report on Business Activities Utilizing Social Media. 2016. URL: https://www.meti.go.jp/english/press/2016/0411 01.html [accessed 2020-03-21] [WebCite Cache ID 715h0JMgy]

63. Yoshihiro I, Yuto T. The management of SNS marketing strategy in Japan [In Japanese]. Bulletin of Yamagata University (Social Science) 2014;45(1):91-127.

64. Medical Institutions Internet Patrol. Ministry of Health, Labour and Welfare Commissioned Project Strengthening Monitoring System of Websites Related to Medical Service, Medical Institutions Internet Patrol [In Japanese]. URL: http:/ /iryoukoukoku-patroll.com/ [accessed 2020-10-19]

65. Ministry of Health, Labour and Welfare. The Internet Patrol Project (2017) [In Japanese]. URL: https://www.mhlw.go.jp/ file/05-Shingikai-10801000-Iseikyoku-Soumuka/0000209654.pdf [accessed 2020-10-19]

66. Omair A. Sample size estimation and sampling techniques for selecting a representative sample. J Health Spec 2014;2(4):142. [doi: 10.4103/1658-600x.142783]

67. Lombard M, Snyder-Duch J, Bracken CC. Content Analysis in Mass Communication: Assessment and Reporting of Intercoder Reliability. Human Comm Res 2002 Oct;28(4):587-604. [doi: 10.1111/j.1468-2958.2002.tb00826.x]

68. Blei DM. Probabilistic topic models. Commun. ACM 2012 Apr 01;55(4):77-84. [doi: 10.1145/2133806.2133826] 
69. Mimno D, Wallach H, Talley E, Leenders M, McCallum A. Optimizing Semantic Coherence in Topic Models. 2011 Jul Presented at: Proceedings of the 2011 Conference on Empirical Methods in Natural Language Processing; July 27-31, 2011; Edinburgh, Scotland, UK.

70. Hanson C, West J, Neiger B, Thackeray R, Barnes M, McIntyre E. Use and Acceptance of Social Media Among Health Educators. American Journal of Health Education 2013 Jan 23;42(4):197-204. [doi: 10.1080/19325037.2011.10599188]

71. The Nikkei. Is "LINE" made in Japan? Made in Korea?. 2013. URL: https://www.nikkei.com/article/ DGXNASFK2203C_S3A120C1000000/ [accessed 2017-10-03]

72. Ministry of Internal Affairs and Communications, Institute for Information and Communications Policy. Survey on usage time and information behavior of information and communication media 2016 [summary] [In Japanese]. 2017. URL: http:/ /www.soumu.go.jp/main_content/000492876.pdf [accessed 2019-08-05]

73. The Nishinippon Shimbun. Iizuka Hospital distributes information about medical care, health and events on LINE every Wednesday [In Japanese]. 2017. URL: https://www.nishinippon.co.jp/nnp/medical/article/344738/ [accessed 2017-07-22]

74. Hu Y, Manikonda L, Kambhampati S. What We Instagram: A First Analysis of Instagram Photo Content and User Types. Palo Alto, California: The AAAI Press; 2014 Presented at: Proceedings of the Eighth International AAAI Conference on Weblogs and Social Media; June 1-4, 2014; Ann Arbor, Michigan, USA.

75. Martinez-Millana A, Fernandez-Llatas C, Basagoiti Bilbao I, Traver Salcedo M, Traver Salcedo V. Evaluating the Social Media Performance of Hospitals in Spain: A Longitudinal and Comparative Study. J Med Internet Res 2017 May 23;19(5):e181 [FREE Full text] [doi: 10.2196/jmir.6763] [Medline: 28536091]

\title{
Abbreviations \\ MAU: Monthly Active Users \\ MHLW: Ministry of Health, Labour and Welfare
}

\author{
Edited by G Eysenbach, Q Zeng; submitted 11.03.20; peer-reviewed by A Martinez-Millana, P Delir Haghighi, JR Bautista; comments \\ to author 28.08.20; revised version received 21.10.20; accepted 25.10.20; published 27.11.20 \\ Please cite as: \\ Sugawara $Y$, Murakami $M$, Narimatsu $H$ \\ Use of Social Media by Hospitals and Clinics in Japan: Descriptive Study \\ JMIR Med Inform 2020;8(11):e18666 \\ URL: https://medinform.jmir.org/2020/11/e18666 \\ doi: $10.2196 / 18666$ \\ PMID: 33245281
}

(C) Yuya Sugawara, Masayasu Murakami, Hiroto Narimatsu. Originally published in JMIR Medical Informatics (http://medinform.jmir.org), 27.11.2020. This is an open-access article distributed under the terms of the Creative Commons Attribution License (https://creativecommons.org/licenses/by/4.0/), which permits unrestricted use, distribution, and reproduction in any medium, provided the original work, first published in JMIR Medical Informatics, is properly cited. The complete bibliographic information, a link to the original publication on http://medinform.jmir.org/, as well as this copyright and license information must be included. 